\title{
Descriptive Capability of Datasets as Proxy of Sea Water Temperature in Coastal Systems: An Evaluation from the Aegean Sea
}

\author{
Fethi Bengil ${ }^{1,2 *}{ }^{\oplus}$, Sinan Mavruk ${ }^{3} \oplus$, Zafer Kızılkaya ${ }^{2}$, Elizabeth G. T. Bengil ${ }^{1,2} \oplus$, Vahit \\ Alan $^{2}\left(\right.$, Inci Tüney Kızılkaya ${ }^{2,4}(0)$
}

${ }^{1}$ Girne American University, Marine School, PK5, Girne, TRNC via Turkey.

${ }^{2}$ Mediterranean Conservation Society, 35100, Bornova, İzmir, Turkey.

${ }^{3}$ Çukurova University, Fisheries Faculty, 01330, Balcalı, Adana, Turkey.

${ }^{4}$ Ege University, Faculty of Science, Department of Biology, 35100, Bornova, Izmir, Turkey.

\section{How to cite}

Bengil, F., Mavruk, S., Kızılkaya, Z., Bengil, E.G.T., Alan, V., KızIlkaya, I.T. (2021). Descriptive Capability of Datasets as Proxy of Sea Water Temperature in Coastal Systems: An Evaluation from the Aegean Sea. Turkish Journal of Fisheries and Aquatic Sciences, 21, 627-635. http://doi.org/10.4194/13032712-v21_12_05

\section{Article History}

Received 22 July 2021

Accepted 11 August 2021

First Online 13 August 2021

\section{Corresponding Author}

Tel.: +903926502000

E-mail: fethibengil@gau.edu.tr

\section{Keywords}

Temperature

Globally available data sets

Proxy

Costal ecosystems

\begin{abstract}
Scientific and technological progresses have introduced diverse data sources for seawater temperature over broad temporal and spatial ranges. Here, we investigated the performance of satellite and model-based seawater temperature data for different temporal composites and depths. We applied an in-situ temperature time-series obtained in a coastal bottom in the Aegean Sea over three years, as the reference. Both datasets showed largely significant relationships based on cross-correlation analyses and presented descriptive properties of the in-situ conditions at corresponding depths. Based on the results of analyses, the modeling datasets presented more reliable results and representations of in-situ conditions than the datasets obtained from satellite for the coastal region. However, the datasets obtained from the satellite also provided reliable data for all time frames investigated, particularly in the mixed surface layer. Monthly datasets were more effective in providing descriptive values in long term studies. This is the first detailed study to explore the descriptive capacities of modeling for water temperature in coastal environments. According to the results, the selection of a dataset as a proxy for seawater temperature requires careful consideration. The present study provides an extensive baseline for evaluating the suitability of the application of specific datasets as proxies in coastal ecosystems.
\end{abstract}

\section{Introduction}

Technological and research progress has provided regular datasets on various variables in marine sciences. For instance, as a source of time-series datasets, satellite oceanography has provided a tool for the continuous monitoring of ocean globally since the 1970s. Therefore, it has become the major tool that has facilitated the development of operational oceanography and its applications (Le Traon, 2018).
Ocean modeling has also recorded similar progress and it has become a vital aspect of operational oceanography over the last 60 years (Le Sommer et al., 2018). Kim et al. (2013) demonstrated that the integration of both data sources could enhance the quality and reliability of the last products.

Although satellite and ocean modeling datasets provide reliable time-series data (e.g. Clementi et al., 2019; Acker \& Leptoukh, 2007), particularly in offshore regions. Current development such European Union 
Copernicus Marine Environment Monitoring Service (CMEMS) reveals products and services for marine studies and applications easily accessible continuous data sets in specific regional domains and temporal coverage in higher resolution. However, there are potential limitations in coastal regions with regard to both types of data sources because of some technical challenges. Coastal regions are more sensitive to retrieve estimations in reasonable uncertainty compared to pelagic zones in offshore as they are relatively shallow. Therefore, the entire water column is affected by interactions among ocean, atmosphere and land. In addition, seawater in coastal regions has more complex dynamics optical properties due to factors that include the influence of terrestrial inputs such as river outflow, spring freshwater outputs and their contaminants. Therefore, such factors could influence overall performance of remote sensing or modeling products in near-coastal areas (Fox-Kemper et al., 2019) and led the unreliability (Baklanov et al., 2011) and, resulted more limited application of remote sensing or modeling techniques in monitoring coastal environments.

Fox-Kemper et al. (2019) have explored novel algorithms, approaches, challenges, and recent progress in ocean modeling, while Lira \& Taborda (2014) reviewed improvements in the resolutions of satellite sensors, which revealed remarkable progress in their potential application in coastal regions. Such progress has made model and algorithm-based approaches available for use in the monitoring of highly dynamic coastal environments, and their application in coastal areas has increased over the last few decades (e.g. Klemas, 2011; Bengil \& Mavruk, 2018, 2019). Though impact of climate change has initiated some attempt to evaluate in order to use satellite derived products for coastal Mediterranean Sea (eg, Von Schuckmann et al., 2019), There is no specific evaluation for products of physical modelling in this manner to the best of our knowledge.

Anthropogenic activities mainly influence the coastal regions of oceans, considering the rich biodiversity and ecological resources found in the regions (Bengil \& Bizsel, 2014). In addition, physical or biogeochemical changes in marine ecosystems linked to climate change are the sources of various stress factors in the ecosystems (Snelgrove et al., 2014). Seawater temperature can be used to evaluate the potential impacts of climate change (GCOS, 2017) on biotic and abiotic components, for example, via mixing and transportation dynamics (Hordoir \& Meier, 2012), match-mismatch mechanisms among different trophic levels (Doney et al., 2012; Durant et al., 2019), structure and composition of local communities (Mavruk et al., 2017), and habitat loss (Mantyka-pringle et al., 2012).

Monitoring seawater temperature is also critical because the products of ocean modeling activities and satellite technologies contain the variable for broad temporal and spatial ranges, which offers an opportunity for the evaluation of the states of sensitive coastal regions under various spatio-temporal ranges at relatively inexpensive costs.

Gökova Bay is located in the transition zone between the South Aegean Sea and the Levantine Sea. The bay is considered a global biodiversity hotspot in the Mediterranean Basin and in the World Wildlife Fund Global 200 ecoregions (Olson \& Dinerstein, 2002). It is the largest Marine Protected Area (MPA) in Turkey (Unal \& Kizilkaya, 2019). In addition to fish biomass and diversity monitoring activities, there are ongoing activities such as active restorations of macroalgae, seagrass habitat, and marine mammal monitoring, as well as abiotic (temperature) components of the ecosystem in the Bay.

The purpose of the present study is to evaluate the capacity of products of ocean modeling and satellite technology to accurately represent coastal seawater temperature data by comparing data obtained from the tools with in-situ reference datasets from a coastal benthic region. We first compared the raw datasets to investigate their utility for descriptive purposes. Afterward, parametrization steps were applied to explore potential calibrations for globally available datasets in the coastal waters of Gökova Bay. In addition, uncertainty properties were also evaluated to understand the capacities of the datasets as proxies from the time frames evaluated in the present study.

\section{Material and Methods}

\section{Datasets}

The study was conducted in the coastal waters of Gökova Bay, south-eastern Aegean Sea (Figure 1). HOBO Pendant water temperature data loggers (Onset Computer Corporation, MA, USA) were deployed just above the sea bottom at five-meter intervals from a depth of five to 40 meters. The loggers were set to collect temperature data at hourly intervals from $01 / 01 / 2016$ to $24 / 10 / 2019$. The data were extracted using HOBOware (Onset Computer Corporation, MA, USA) data acquisition software. Daily, weekly (8 days), and monthly averages were calculated from the extracted data. The obtained datasets were then used to compare various time series data-sets from numerical physical models and satellite images.

Datasets from modeling and satellite technologies used in the present study were obtained from global data services. With regard to the modeling dataset, temperature products, which were composed of 24hour mean fields and monthly mean fields, from the Mediterranean Sea Physical Forecasting system (MEDSEA_ANALYSIS_FORECAST_PHY_006_013) that was generated by Clementi et al. (2019) under European Union Copernicus Marine Environment Monitoring Service (CMEMS) framework. Product were chosen since it is developed for the Mediterranean Sea with reasonable good spatial resolution (ca. $4 \mathrm{~km}$ ), which is 
required to demonstrate some certain coastal structures. The data were extracted to match in-situ datasets in daily, weekly, and monthly time frames from $01 / 01 / 2017$ to $24 / 10 / 2019$. Since they were not available in the model fields, weekly products were generated using daily products of the model dataset by calculating average values for relevant time frames. Subsequently, linear interpolation was used to generate modeling data at exact depths, where loggers were deployed, since the model has outputs for 141 fixed vertical depth layers. The datasets obtained from models were compared with in-situ datasets at relevant time frames and periods based on the geographical locations of the stations and depths. Detailed information on the datasets can be obtained in the product user manual for the Mediterranean Sea Physical and Forecasting Product (CMEMS-MED, 2018).

Datasets retrieved from satellite images are available only for the sea surface. Therefore, the datasets for the surface were matched with in-situ datasets at each depth. However, data for some days were missing due to the atmospheric conditions at the time of passing the satellite sensors overhead. To minimize dataset losses, level three multi sensor product (Orain \& Picart 2019; SST_EUR_SST_L3S_NRT_OBSERVATIONS_010_009_A) of CMEMS was used when comparing the data with the in-situ data at daily resolution. Products for weekly and monthly sea surface temperature were obtained using the Giovanni online data system, which was developed and is maintained by the Goddard Earth Sciences Data and Information Services Center (GES DISC) of NASA (see Acker \& Leptoukh, 2007), at 11 ?m Moderate Resolution Imaging Spectroradiometer on board the aqua satellite. Data from all products were extracted and matched with in-situ data from 01/01/2016 to 24/10/2019.

\section{Statistical Analysis}

To analyze the descriptive performance of the model and satellite-based datasets, Welch's two independent samples t-test and Levene's test for homogeneity of variance were performed for the differences between the overall mean and variance values of temperature obtained in-situ and calculated from the model or satellite-based datasets. The different composites of the same dataset were also compared using the same approach. To detect the performance of the model and satellite-based datasets in tracking changes in temperature, cross-correlation functions (CCF) between the variable pairs composed of the corresponding depths of the in-situ (independent variable, $x_{t+1}$ ) and the model/satellite-based (dependent variable, $y_{t}$ ) datasets were calculated up to a 10-time

Table 1. Descriptive statistics of temperature data sets in time frames $\left({ }^{\circ} \mathrm{C}\right)$

\begin{tabular}{|c|c|c|c|c|c|c|c|c|c|c|c|c|}
\hline \multirow{3}{*}{$\begin{array}{l}\text { Daily } \\
\text { Depth } \\
\text { Surface }\end{array}$} & \multicolumn{4}{|c|}{$\begin{array}{c}\text { In-situ } \\
(01 / 01 / 2016-24 / 10 / 2019)(N=1392)\end{array}$} & \multicolumn{4}{|c|}{$\begin{array}{c}\text { Physical Model } \\
\text { (01/01/2017-24/10/2019) ( } N=1027)\end{array}$} & \multicolumn{4}{|c|}{$\begin{array}{c}\text { Satellite image } \\
(01 / 01 / 2016-24 / 10 / 2019)(\mathrm{N}=1075)\end{array}$} \\
\hline & Min & Mean & SD & Max & Min & Mean & SD & Max & Min & Mean & SD & Max \\
\hline & & & & & & & & & 15.80 & 23.33 & 4.14 & 29.41 \\
\hline 5 & 15.98 & 21.79 & 4.02 & 28.77 & 16.72 & 21.85 & 3.58 & 28.67 & & & & \\
\hline 10 & 16.00 & 21.51 & 3.81 & 28.48 & 16.72 & 21.61 & 3.41 & 27.76 & & & & \\
\hline 15 & 15.98 & 21.22 & 3.59 & 27.80 & 16.72 & 21.32 & 3.20 & 27.31 & & & & \\
\hline 20 & 15.99 & 20.93 & 3.40 & 27.49 & 16.72 & 20.90 & 2.91 & 26.66 & & & & \\
\hline 25 & 15.96 & 20.45 & 3.11 & 27.11 & 16.72 & 20.42 & 2.58 & 26.17 & & & & \\
\hline 30 & 15.97 & 20.00 & 2.78 & 26.65 & 16.73 & 19.98 & 2.27 & 25.09 & & & & \\
\hline 35 & 15.95 & 19.58 & 2.43 & 26.10 & 16.75 & 19.65 & 2.01 & 24.92 & & & & \\
\hline 40 & 15.94 & 19.13 & 2.01 & 24.76 & 16.76 & 19.40 & 1.80 & 24.77 & & & & \\
\hline Weekly & \multicolumn{4}{|c|}{ In-situ ( $N=175)$} & \multicolumn{4}{|c|}{ Physical Model $(\mathrm{N}=129)$} & \multicolumn{4}{|c|}{ Satellite image ( $N=175)$} \\
\hline Surface & & & & & & & & & 15.22 & 21.14 & 4.09 & 27.71 \\
\hline 5 & 16.15 & 21.76 & 4.02 & 28.31 & 16.86 & 21.83 & 3.58 & 28.12 & & & & \\
\hline 10 & 16.23 & 21.48 & 3.81 & 27.87 & 16.84 & 21.60 & 3.41 & 27.48 & & & & \\
\hline 15 & 16.22 & 21.20 & 3.58 & 27.47 & 16.83 & 21.31 & 3.19 & 26.93 & & & & \\
\hline 20 & 16.23 & 20.91 & 3.36 & 26.94 & 16.83 & 20.89 & 2.88 & 26.25 & & & & \\
\hline 25 & 16.20 & 20.43 & 3.05 & 26.50 & 16.82 & 20.41 & 2.54 & 25.09 & & & & \\
\hline 30 & 16.21 & 19.99 & 2.69 & 26.10 & 16.82 & 19.97 & 2.23 & 24.89 & & & & \\
\hline 35 & 16.19 & 19.57 & 2.34 & 25.01 & 16.82 & 19.65 & 1.97 & 24.61 & & & & \\
\hline 40 & 16.17 & 19.12 & 1.94 & 24.08 & 16.82 & 19.39 & 1.76 & 24.24 & & & & \\
\hline Monthly & \multicolumn{4}{|c|}{ In-situ (N=45) } & \multicolumn{4}{|c|}{ Physical Model (N=33) } & \multicolumn{4}{|c|}{ Satellite image $(\mathrm{N}=45)$} \\
\hline Surface & & & & & & & & & 15.57 & 21.17 & 4.07 & 27.50 \\
\hline 5 & 16.37 & 21.71 & 4.02 & 27.83 & 16.98 & 21.75 & 3.6 & 27.66 & & & & \\
\hline 10 & 16.37 & 21.42 & 3.80 & 27.39 & 16.96 & 21.51 & 3.41 & 26.93 & & & & \\
\hline 15 & 16.40 & 21.14 & 3.56 & 26.87 & 16.96 & 21.22 & 3.18 & 26.49 & & & & \\
\hline 20 & 16.41 & 20.84 & 3.33 & 26.29 & 16.94 & 20.79 & 2.85 & 25.81 & & & & \\
\hline 25 & 16.36 & 20.36 & 3.00 & 25.61 & 16.93 & 20.31 & 2.48 & 24.77 & & & & \\
\hline 30 & 16.37 & 19.93 & 2.63 & 24.80 & 16.93 & 19.87 & 2.14 & 23.94 & & & & \\
\hline 35 & 16.35 & 19.51 & 2.27 & 23.89 & 16.92 & 19.55 & 1.88 & 23.37 & & & & \\
\hline 40 & 16.32 & 19.07 & 1.87 & 22.82 & 16.93 & 19.31 & 1.68 & 22.68 & & & & \\
\hline
\end{tabular}


unit lag distance (I). Before the analysis, the datasets were checked for stationarity and temporal independence using the Kwiatkowski-Phillips-SchmidtShin (KPSS) test (Kwiatkowski et al., 1992; Trapletti \& Hornik, 2019) and autocorrelation function analysis (Zuur et al., 2009), respectively. Both the assumptions were not satisfied in nearly all the variable pairs. To avoid obtaining spurious correlations and unreliable significance values, pre-whitening (AR1) was applied to each variable pair after the first differences between the variables were calculated (Dean \& Dunsmuir, 2016) using R library TSA (Chan \& Ripley, 2018). All statistical analyses were performed using R v3.0.2 (R Core Team, 2019).

In the case of significant correlations between two datasets, linear regression parameters were calculated to suggest a possible calibration approach for the data on the coastal waters of Gökova Bay. Uncertainty properties of model and satellite datasets were also evaluated to understand capability of utilization time frames in the present study.

\section{Results}

Minimum, mean, standard deviation (SD) and maximum of all data sets in each time frame and depth were presented in Table 1 in order to provide descriptive summary. The performance of the model-based dataset in estimating average values of in-situ was good. Based on pairwise Welch two-sample t-tests, there was no significant difference between mean values calculated from the in-situ and the model-based datasets at any depth or any time frame. The only exception was at a depth of $40 \mathrm{~m}$ based on daily datasets, where the model overestimated mean value significantly $(p<0.01)$. The variances in temperature, when compared with the insitu temperature, were significantly higher at all depths in the daily and weekly datasets $(p<0.05)$, excluding the weekly comparison at $40 \mathrm{~m}$. However, no significant differences in variance were observed in the monthly datasets (Table S1 in Supplement file).

Satellite-based datasets performed relatively poor in estimating the descriptive characteristics of seawater temperature in Gökova Bay, which was particularly apparent in the daily datasets where the surface datasets of the satellite images showed significantly overestimated mean values $(p<0.001)$ when compared with in-situ datasets at all depths in the daily time frame. The performance of the satellite data increased in weekly and monthly composites when compared with the daily composites. However, significantly overestimated mean values of the satellite dataset were observed after a depth of $30 \mathrm{~m}$ in the weekly time frame $(p<0.001)$ and after a depth of $35 \mathrm{~m}$ in the monthly time frame $(p<0.01)$. Based on the Levene's test of homogeneity of variance, the variances of temperature calculated from the satellite dataset were higher at all depths in the daily and the weekly time frames $(p<0.001)$, while the variances were significantly higher only at depths greater than $25 \mathrm{~m}$ in the monthly time frame $(p<0.001)$ (Table S2 in Supplement file).

In in-situ and model-based datasets, the overall mean and variance values calculated from daily, weekly, and monthly composites were not significantly different. However, daily datasets derived from satellite images produced significantly higher overall mean values $\left(23.33 \pm 0.25 ; \pm 0.95^{\circ} \mathrm{C}\right.$ confidence intervals, ci) in comparison to the weekly $\left(21.14 \pm 0.61^{\circ} \mathrm{C}\right)$ and monthly $\left(21.17 \pm 1.19^{\circ} \mathrm{C}\right)$ time frames $(p<0.001)$ (Table S3 in Supplement file).

Results from CCFs showed mostly significant relationships between the variable pairs composed of the corresponding depth layers of the different data sources (Table 2). In general, model-based data yielded higher CCF values with in-situ data in the daily and weekly composites. In the daily composites, the in-situ data statistically led model-based data with a one-day lag at 5 and 10-m depths, whereas both datasets revealed synchrony at deeper layers. Overall, weekly composite model-based data provided the highest CCF values at all depths without time lags ( $C C F=0.65-0.81$; $\mathrm{p}<0.001$; lag $=0$ ). The performance of the satellite-based data decreased gradually with an increase in depth; where the model always provided better estimates in deeper waters. Notably, satellite data statistically led the in-situ dataset with one or two-week lags between

Table 2. Coefficients of CCF for each pair of variables in data sets.

\begin{tabular}{|c|c|c|c|c|c|c|}
\hline \multirow[b]{2}{*}{ Depth } & \multicolumn{2}{|c|}{ Daily } & \multicolumn{2}{|c|}{ Weekly } & \multicolumn{2}{|c|}{ Monthly } \\
\hline & in-situ vs model & $\begin{array}{c}\text { in-situ vs } \\
\text { satellite }^{+, \phi}\end{array}$ & in-situ vs model & $\begin{array}{l}\text { in-situ vs } \\
\text { satellite }^{+}\end{array}$ & in-situ vs model & $\begin{array}{l}\text { in-situ vs } \\
\text { satellite }^{+}\end{array}$ \\
\hline $5 \mathrm{~m}$ & $0.45^{* * *}(-1)$ & $0.14 * * *(0)$ & $0.77^{* * *}(0)$ & $0.49 * * *(1)$ & $-0.56 *(1)$ & $0.56^{* *(1)}$ \\
\hline $10 \mathrm{~m}$ & $0.42 * * *(-1)$ & $0.10 * *(0)$ & $0.80 * * *(0)$ & $0.34 * * *(1)$ & $-0.48 *(4)$ & $-0.55 * *(-1)$ \\
\hline $15 \mathrm{~m}$ & $0.43^{* * *}(0)$ & $0.11^{* *}(0)$ & $0.81 * * *(0)$ & $0.29 * * *(2)$ & $0.68 * * *(0)$ & $0.46 * *(1)$ \\
\hline $20 \mathrm{~m}$ & $0.51 * * *(0)$ & $0.08 *(0)$ & $0.70 * * *(0)$ & $0.35 * * *(1)$ & $-0.55 *(-7)$ & $0.48 * *(1)$ \\
\hline $25 \mathrm{~m}$ & $0.57 * * *(0)$ & $0.09 * *(0)$ & $0.65 * * *(0)$ & $0.21 * *(0)$ & ns & ns \\
\hline $30 \mathrm{~m}$ & $0.61 * * *(0)$ & $0.12 * * *(0)$ & $0.65 * * *(0)$ & $0.20 * *(7)$ & ns & ns \\
\hline $35 \mathrm{~m}$ & $0.58 * * *(0)$ & $0.08 * *(0)$ & $0.72 * * *(0)$ & $0.22 * *(7)$ & ns & ns \\
\hline $40 \mathrm{~m}$ & $0.55 * * *(0)$ & $0.06 *(0)$ & $0.77 * * *(0)$ & $0.28 * * *(7)$ & ns & ns \\
\hline
\end{tabular}

${ }^{+}$Data set from satellite images corresponds only surface layer in each comparison; values in parenthesis indicate lag distance which give the

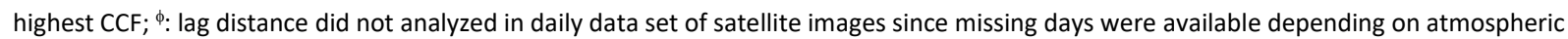
conditions; ${ }^{*}$ shows significant at $p<0.05 ;{ }^{* *}$ shows significant at $p<0.01 ;{ }^{* *}$ shows significant at $p<0.001 ;$ ns indicated CCF is not significant. 
the 5 and 20-m depths. The CCFs of monthly composites mostly yielded non-significant results below $25 \mathrm{~m}$. Moreover, apparently unrealistic results were observed between the 5 and 20-m depths, such as negative correlations and high optimal lag distances (Table 2, Figure S1 and S2 in Supplement file).
High values of coefficients of determination were observed in the regression analysis for significant relationships determined in the CCF analysis. Coefficients of determination were dispersed between 0.47 (satellite dataset in $40 \mathrm{~m}$ ) and 0.98 (modeling dataset in 5-10 m) for relationships between datasets

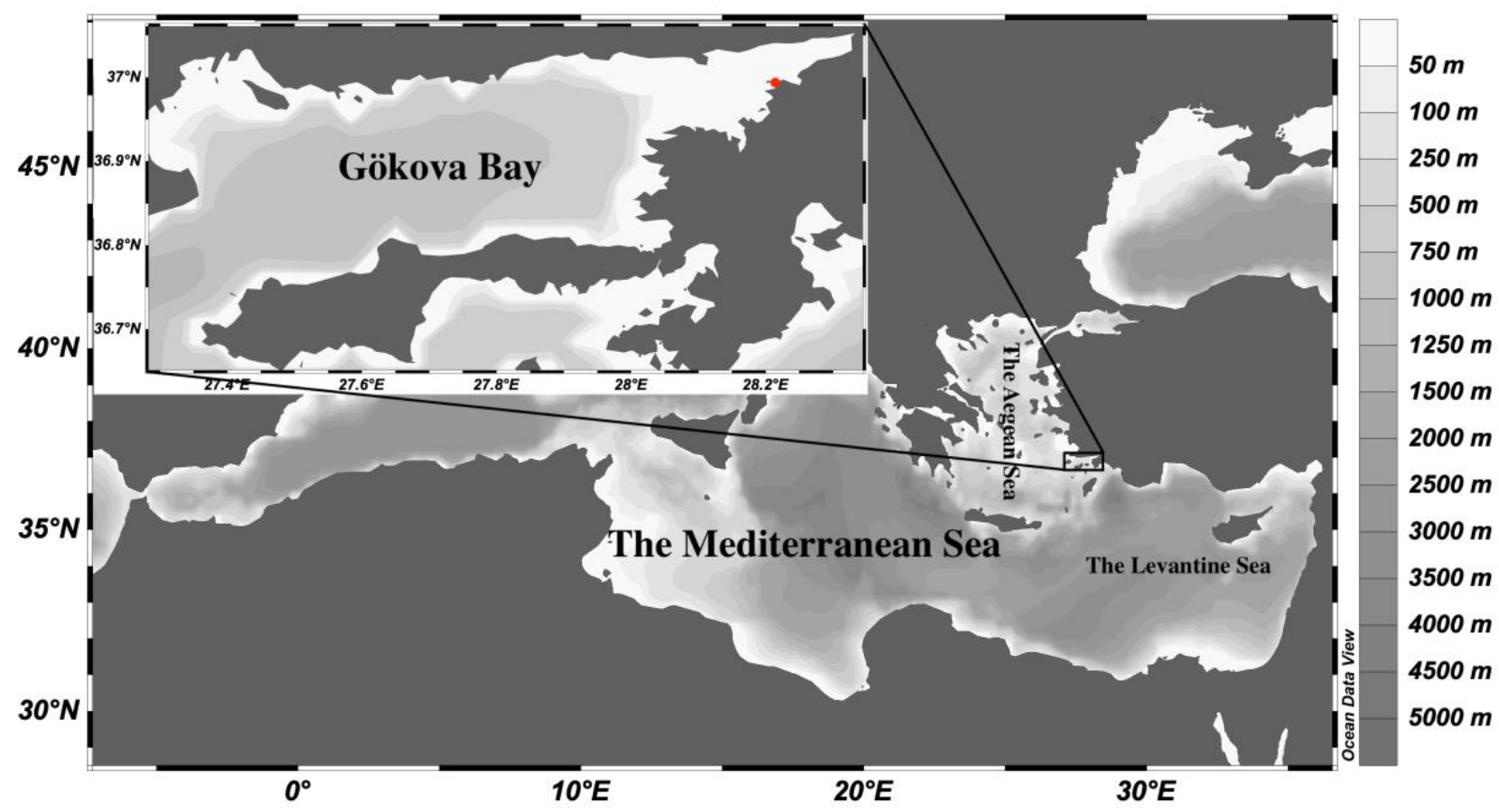

Figure 1 The study area. Red circle indicates the station where temperature data loggers were deployed (36.958 N-28.189 E)
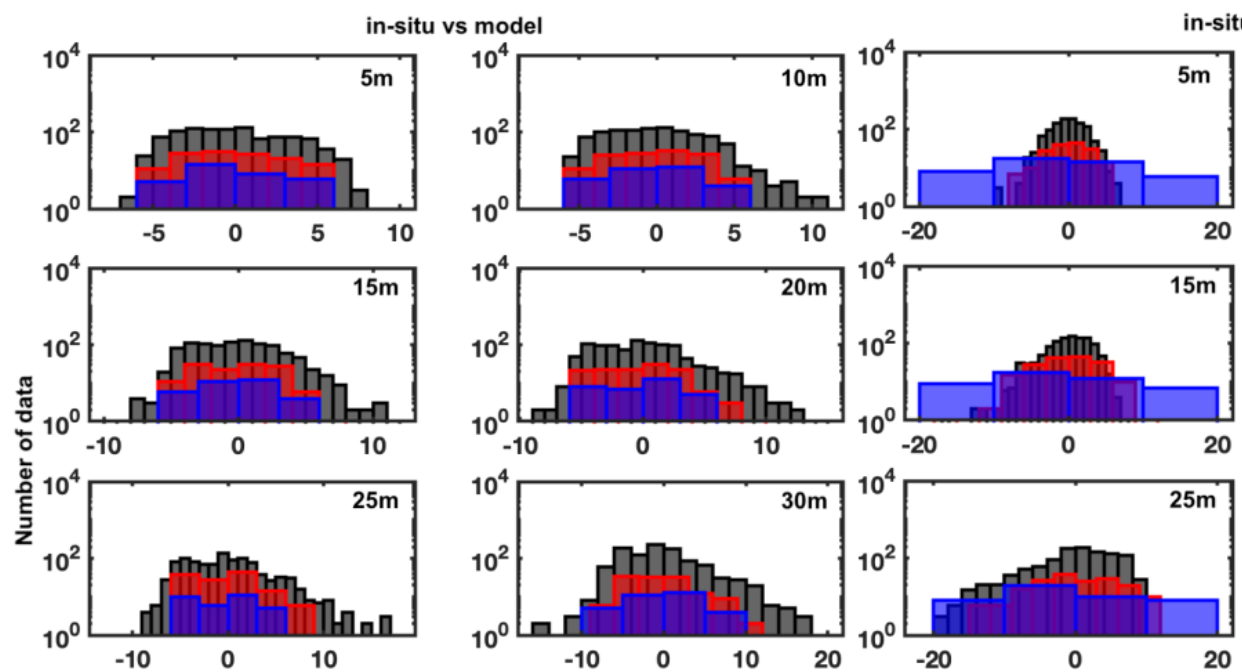

in-situ vs satellite
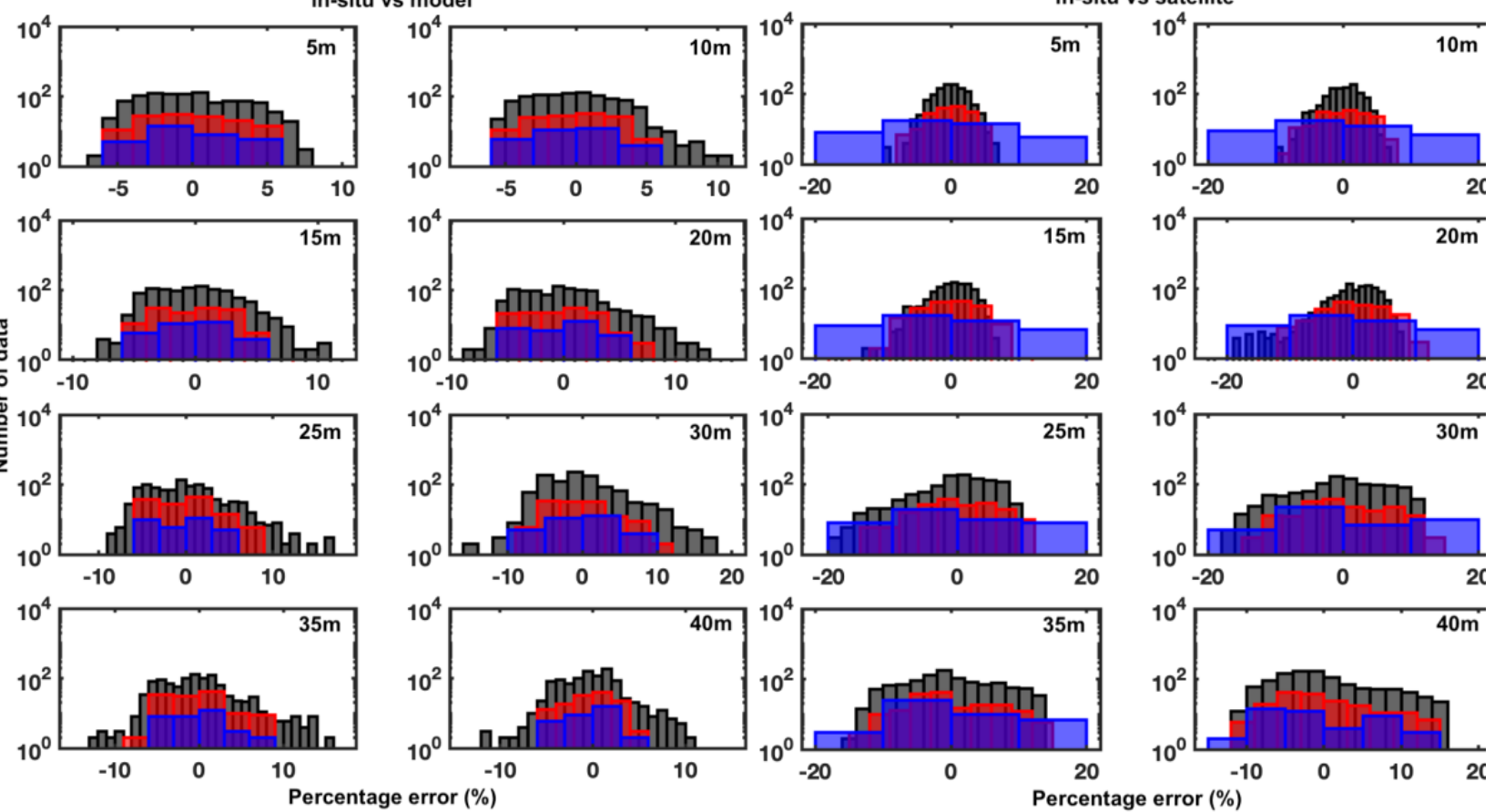

Figure 2. Distribution of percentage errors for all comparisons. Grey bars indicate daily comparisons; red bars show weekly comparisons; blue bars indicate monthly comparisons. Each depth comparison with satellite data set corresponds to surface data set for satellite. 
within each temporal frame (Table S4 in Supplement file). Comparisons of dataset pairs across the time frames are presented in Figures S3 and S4 in Supplement file.

The narrowest percentage error $(9.04 \%)$ was observed at 5-m depth in monthly comparisons, while the broadest range in error distribution was $35.00 \%$ at $30 \mathrm{~m}$ depth in daily comparisons between the in-situ and modeling datasets. Monthly modeling datasets had the optimal performance in error among all time frames. Distributions of percentage error ranged from $16.88 \%$ to $33.89 \%$ for comparisons between the in-situ and the satellite image datasets. Comparisons also revealed that daily datasets had superior performance based on percentage error, and the performance increased gradually when compared with the monthly datasets (Table S5 in Supplement file). Mean value of percentage error was also observed to be close to zero for all comparisons, and none of them showed overall underestimation or overestimation based on all the time frames examined.

\section{Discussion}

There have been previous successful and unsuccessful attempts to exploit globally available datasets for coastal systems throughout the marine regions globally. Smale \& Wernberg (2009) tested satellite image-based datasets in an attempt to apply them as proxy of sea water temperature for ecological studies on coastal benthic fauna and found an overall ability to detect large scale patterns of ecological importance. They also explored their limitations. Thakur et al. (2018) provided an extensive comparison for sea surface temperature and salinity based on in-situ and satellite datasets to determine the most appropriate satellite products that could be applied in aquaculture systems. In addition, Stobart et al. (2015) made an extensive comparison throughout the coastal region of Australia. Although they observed satellite datasets to be potentially valid proxies for in-situ datasets for benthic habitats with acceptable uncertainty limits, they pointed out some major factors to consider when using satellite image-based data as proxy for some specific purposes such ecological modeling. Satellite products were observed to be unreliable proxy in shallow coastal waters of South Africa by Smit et al. (2013).

The Mediterranean has minimal studies evaluating the reliability of satellite images in the coastal regions (e.g., Dassenakis et al., 2011; Bengil \& Bizsel, 2014). Matarrese et al. (2004) found good consistency between satellite-based data and interpolated in-situ datasets via regional physical modeling in semi-enclosed coastal waters in Italy. Recently, an extensive comparison between in-situ measurements and satellite products for assessing of climate change effect in marine protected areas throughout the Mediterranean to evaluate applicability of a certain satellite derived product in onshore region (Von Schuckmann et al.,
2019). In addition, no specific studies have evaluated the reliability of the model used in the present study in the coastal regions in the eastern, although there have been validated models for the Mediterranean (e.g. Clementi et al., 2019). In addition, no study has evaluated the performance of globally available datasets for their reliability as proxies for seawater temperature at various depths in benthic ecosystems.

To the best of our knowledge, this is the first study to explore the descriptive capacity of modeling products in a coastal benthic ecosystem. According to the results, modeling products exhibit good performance in the representation of descriptive characteristics of seawater temperature in coastal benthic regions. The insignificant differences in mean values of each variable pairs (excluding at $40 \mathrm{~m}$ ) further support the application of model datasets for descriptive purposes in further studies. The time frame of the dataset could be determined based on the period of study or the sampling strategy adopted in a study in a coastal region. However, daily modeling datasets overestimated the mean value of seawater temperature at $40-\mathrm{m}$ depth, which indicated that the modeling products could only be applied to a certain depth. Conversely, this significant difference disappeared at decreased temporal resolutions. As expected, smoother distributions in datasets were observed under decreasing temporal resolutions. The smoothness is the reason for the nonsignificant difference in mean values in the weekly and monthly datasets at $40 \mathrm{~m}$. The overall results of comparisons of variance also highlighted the importance of selecting the appropriate time frame. It is also critical to consider that the model underestimated variance properties under the daily and weekly time frames and variance properties at $40 \mathrm{~m}$ in the model were underestimated within the weekly time frame. The observation raises another concern on the use of modeling datasets after a certain depth.

The results raised key concerns regarding the usability of satellite datasets for descriptive purposes. The daily time frame overestimated mean values significantly in all comparisons with the in-situ datasets. Previous studies globally have reported that satellite image-based datasets tend to overestimate temperature data (Smale \& Wernberg, 2009; Smit et al., 2013; Stobart et al., 2015). However, we observed that the mean values from satellite images could be used as proxies of sea surface temperatures down to $25 \mathrm{~m}$ based on weekly datasets and down to $35 \mathrm{~m}$ based on monthly datasets. Significant differences in descriptive characteristics of datasets between the daily and the other time frames could be attributed to the used of datasets from different sources. With regard to the descriptive properties of seawater temperature, variance with satellite image-based datasets was also higher than the variance with in-situ datasets, particularly in the comparisons in the daily and weekly time frames. Although satellite datasets deviate from actual sea water temperature values with an increase in 
depth (Katsaros, 2003), in general, of the use of weekly and monthly datasets from satellite images in the upper layers is possible, and of the use of daily dataset for descriptive purpose as proxies of seawater temperature should be avoided.

Another limitation of satellite-based datasets on a daily time frame, atmospheric conditions could affect the retrieval of signals on a daily basis leading to missing data. Missing data could also limit the use of such datasets for other purposes such as time series analyses, which require complete datasets.

Significant relationships were observed mostly between pairs of datasets at similar depths. The monthly dataset exhibited relatively poor performance while the optimal performance was observed in the weekly dataset, which had relatively high CCF values with no lag. With regard to the time frame, similar performance was also observed in the satellite imagebased datasets. However, the vertical performance of the satellite datasets decreased gradually depending on depth, where more reliable relationships were observed up to $25 \mathrm{~m}$. In addition, the model exhibited performance superior to the satellite-based datasets as proxies for seawater temperature at all time frames and depths.

A technical limitation of satellite images is that they provide data only for the surface layer, which leads to relatively poor or invalid performance at depths greater than $20 \mathrm{~m}$. Sayın et al. (2006) reported the formation of a sharp and seasonally stratified thermocline between $20 \mathrm{~m}$ and $35 \mathrm{~m}$ in a coastal region of the Aegean Sea. Therefore, it can be concluded that using such datasets in the upper mixed layer as a proxy of seawater temperature could offer more reliable results for further studies in the coastal benthic regions.

Distribution in percentage errors in pairs of datasets at each depth and time frame revealed a high uncertainty level, particularly down to $25 \mathrm{~m}$ in the monthly time frame in the satellite-based data, which further demonstrates why they should not be adopted in further studies. Such distributions (Figure 2) also provide guides on the uncertainty levels of different sources of dataset and could facilitate the design of further studies. In case these datasets need to be used at a certain depth for descriptive purposes, a correction procedure can be applied to the relevant datasets using regression coefficients presented in this study (Table S4 in Supplement file).

Stobart et al. (2015) pointed out the importance of suitability in temporal resolution between a research and datasets that will be used. They suggested the use of satellite data for broad time frames such annual rather than seasonal and monthly scales, considering the lack of information in the latter temporal frames. Our study focuses on daily to monthly time frames and discusses in detail the advantages and disadvantages of such time frames with regard to the reliability as proxies of descriptive characteristics. Overall, our results pointed out the advantages of the use of the weekly time frame as moderate. Conversely, as the broad time frame in the present study, the monthly time frame could have limited performance based on the aims of the study in which it would be applied. In addition, the uncertainty properties of satellite datasets for time frames revealed broad ranges of percentage errors in the monthly dataset (Figure 2), although it was reliable as a proxy for descriptive characteristics and had significant a relationship with the in-situ datasets in the surface mixed layer. Therefore, the use of the datasets, particularly the satellite-based dataset, in coastal regions should be considered carefully depending on the type of study, especially for bio-ecological modeling and climate change studies.

\section{Conclusion}

Comparisons of the descriptive characteristics of datasets from various data sources in the present study revealed their advantages and disadvantages under different time frames. Datasets from physical models had more reliable results and capacity to represent insitu data in coastal benthic habitats. In addition, satellite-based datasets could also be used under key considerations. Monthly datasets are more reliable as sources of mean and variance values in long term studies, while weekly datasets are suitable for monitoring studies since changes can be detected. Although reasonable relationships were discerned in the surface mixed layer, datasets from the model could also be adopted when presentations below seasonal thermocline are required. Uncertainty analysis also revealed that modeling datasets have key advantages at each depth based on percentage error. Where required, the calibration coefficients presented in this study could be used to provide more accurate characterization at certain depths based on their uncertainty limits in future studies.

The present study presents an important resource on the suitability of adopting globally available datasets for descriptive purposes under different time composites as well as presenting their reliability based on the uncertainty properties in the eastern Mediterranean Basin, particularly in the eastern Aegean Sea. The baseline presented highlights the potential application of global datasets as proxies of seawater temperature in future coastal benthic ecology and conservation studies.

\section{Ethical Statement}

This study does not require an ethical statement.

\section{Funding Information}

This study was inspired, motivated, and supported by the EU Horizon 2020 Research and Innovation Program: MERCES (full title: Marine Ecosystem Restoration in Changing European Seas; Grant 
agreement no: 689518) and published as a contribution to the project efforts. We are very grateful to MEDPAN for providing temperature devices.

\section{Author Contribution}

All Authors contributed equally.

\section{Conflict of Interest}

The author(s) declare that they have no known competing financial or nonfinancial, professional, or personal conflicts that could have appeared to influence the work reported in this paper

\section{Acknowledgements}

This study was inspired, motivated, and supported by the EU Horizon 2020 Research and Innovation Program: MERCES (full title: Marine Ecosystem Restoration in Changing European Seas; Grant agreement no: 689518) and published as a contribution to the project efforts. We are very grateful to MEDPAN for providing temperature devices.

\section{References}

Acker, J. G., \& Leptoukh, G. (2007). Online Analysis Enhances Use of NASA Earth Science Data. Eos, Transactions American Geophysical Union, 88(2), 14. https://doi.org/10.1029/2007EO020003

Baklanov, A. A., Grisogono, B., Bornstein, R., Mahrt, L., Zilitinkevich, S. S., Taylor, P., Larsen, S. E., Rotach, M. W., \& Fernando, H. J. S. (2011). The Nature, Theory, and Modeling of Atmospheric Planetary Boundary Layers. Bulletin of the American Meteorological Society, 92(2), 123-128. https://doi.org/10.1175/2010BAMS2797.1

Beck, M., \& Airoldi, L. (2007). Loss, Status and Trends for Coastal Marine Habitats of Europe. In R. N. Gibson, J. A. Atkinson, \& D. M. Gordon (Eds.), Oceanography and Marine Biology: An Annual Review (pp. 345-405). Taylor \& Francis. https://doi.org/10.1201/9781420050943.ch7

Bengil, F., \& Bizsel, K. (2014). Assessing the impact of aquaculture farms using remote sensing: an empirical neural network algorithm for Ildırı Bay, Turkey. Aquaculture Environment Interactions, 6(1), 67-79. https://doi.org/10.3354/aei00115

Bengil, F., \& Mavruk, S. (2018). Bio-optical trends of seas around Turkey: An assessment of the spatial and temporal variability. Oceanologia, 60(4), 488-499. https://doi.org/10.1016/j.oceano.2018.03.004

Bengil, F., \& Mavruk, S. (2019). Warming in Turkish seas: comparative multidecadal assessment. Turkish Journal of Fisheries and Aquatic Sciences, 19(1), 51-57. https://doi.org/10.4194/1303-2712-v19_1_06

Chan, K. S., \& Ripley, B. (2018). TSA: Time Series Analysis (p. R package version 1.2). $R$ package version 1.2.

Clementi, E., Pistoia, J., Escudier, R., Delrosso, D., Drudi, M., Grandi, A., Lecci, R., Cretí, S., Ciliberti, S., Coppini, G., Masina, S., \& Pinardi, N. (2019). Mediterranean Sea Analysis and Forecast (CMEMS MED-Currents 20162019) [Data set].
https://doi.org/10.25423/CMCC/MEDSEA_ANALYSIS_F ORECAST_PHY_006_013_EAS4

CMEMS-MED. (2018). Product User Manual for Mediterranean Sea Physical Analysis and Forecasting Product.

Cook, A., Parsons, M., Mitchell, I., \& Robinson, R. (2011). Reconciling policy with ecological requirements in biodiversity monitoring. Marine Ecology Progress Series, 434, 267-277. https://doi.org/10.3354/meps09244

Dassenakis, M., Paraskevopoulou, V., Cartalis, C., Adaktilou, N., \& Katsiabani, K. (2011). Remote sensing in coastal water monitoring: Applications in the eastern Mediterranean Sea (IUPAC Technical Report). Pure and Applied Chemistry, 84(2), 335-375. https://doi.org/10.1351/PAC-REP-11-01-11

Dean, R. T., \& Dunsmuir, W. T. M. (2016). Dangers and uses of cross-correlation in analyzing time series in perception, performance, movement, and neuroscience: The importance of constructing transfer function autoregressive models. Behavior Research Methods, 48(2), 783-802. https://doi.org/10.3758/s13428-0150611-2

Doney, S. C., Ruckelshaus, M., Emmett Duffy, J., Barry, J. P., Chan, F., English, C. A., Galindo, H. M., Grebmeier, J. M., Hollowed, A. B., Knowlton, N., Polovina, J., Rabalais, N. N., Sydeman, W. J., \& Talley, L. D. (2012). Climate Change Impacts on Marine Ecosystems. Annual Review of Marine Science, 4(1), 11-37. https://doi.org/10.1146/annurev-marine-041911111611

Durant, J. M., Molinero, J.-C., Ottersen, G., Reygondeau, G., Stige, L. C., \& Langangen, $\varnothing$. (2019). Contrasting effects of rising temperatures on trophic interactions in marine ecosystems. Scientific Reports, 9(1), 15213. https://doi.org/10.1038/s41598-019-51607-w

Fox-Kemper, B., Adcroft, A., Böning, C. W., Chassignet, E. P., Curchitser, E., Danabasoglu, G., Eden, C., England, M. H., Gerdes, R., Greatbatch, R. J., Griffies, S. M., Hallberg, R. W., Hanert, E., Heimbach, P., Hewitt, H. T., Hill, C. N., Komuro, Y., Legg, S., Le Sommer, J., ... Yeager, S. G. (2019). Challenges and Prospects in Ocean Circulation Models. Frontiers in Marine Science, 6:65, 1-29. https://doi.org/10.3389/fmars.2019.00065

GCOS. (2017). Indicators of Climate Change. GLOBAL CLIMATE OBSERVING SYSTEM of World Meteorological Organization.

https://library.wmo.int/doc_num.php?explnum_id=341 8.

Hordoir, R., \& Meier, H. E. M. (2012). Effect of climate change on the thermal stratification of the baltic sea: a sensitivity experiment. Climate Dynamics, 38(9-10), 1703-1713. https://doi.org/10.1007/s00382-011-1036y

Katsaros, K. B. (2003). Satellite Versus In Situ Measurements at the Air-Sea Interface. In T. D. Potter \& B. R. Colman (Eds.), Handbook of Weather, Climate, and Water (pp. 885-893). John Wiley \& Sons, Inc. https://doi.org/10.1002/0471721603.ch47

Keiner, L. E., \& Yan, X.-H. (1998). A Neural Network Model for Estimating Sea Surface Chlorophyll and Sediments from Thematic Mapper Imagery. Remote Sensing of Environment, 66(2), 153-165. https://doi.org/10.1016/S0034-4257(98)00054-6

Kim, C. S., Park, Y.-J., Park, K. S., Shim, J. S., \& Lim, H.-S. (2013). Application of $\mathrm{GOCl}$ Satellite Data to Ocean Modeling. 
Journal of Coastal Research, 165, 1409-1414. https://doi.org/10.2112/SI65-238.1

Kizilkaya, Z., Unal, V., \& Yildirim, D. (2015). Three years' experience with small-scale fishers and no-take-zones in Gökova Bay (eastern Mediterranean), Turkey. In A. Srour, N. Ferri, D. Bourdenet, D. Fezzardi, \& A. Nastasi (Eds.), First regional symposium on sustainable smallscale fisheries in the Mediterranean and Black Sea. FAO (Food and Agriculture Organization of the United Nations) Fish-eries and Aquaculture Proceedings 39 (pp. 297-305). FAO Fisheries and Aquaculture Proceeding 39.

Klemas, V. (2011). Remote sensing techniques for studying coastal ecosystems: an overview. Journal of Coastal Research, 27(1), 2-17.

https://doi.org/10.2112/JCOASTRES-D-10-00103

Kwiatkowski, D., Phillips, P. C. B., Schmidt, P., \& Shin, Y. (1992). Testing the null hypothesis of stationarity against the alternative of a unit root. Journal of Econometrics, 54(13), 159-178. https://doi.org/10.1016/0304-4076(92)90104-Y

Le Sommer, J., Chassignet, E. P., \& Wallcraft, A. J. (2018). Ocean Circulation Modeling for Operational Oceanography: Current Status and Future Challenges. In New Frontiers in Operational Oceanography (pp. 289306). GODAE OceanView. https://doi.org/10.17125/gov2018.ch12

Le Traon, P.-Y. (2018). Satellites and Operational Oceanography. In New Frontiers in Operational Oceanography (pp. 161-190). GODAE OceanView. https://doi.org/10.17125/gov2018.ch07

Leach, K., Montgomery, W. I., \& Reid, N. (2016). Modelling the influence of biotic factors on species distribution patterns. Ecological Modelling, 337, 96-106. https://doi.org/10.1016/j.ecolmodel.2016.06.008

Lira, C., \& Taborda, R. (2014). Advances in Applied Remote Sensing to Coastal Environments Using Free Satellite Imagery. In C. W. Finkl \& C. Makowski (Eds.), Advances in Coastal and Marine Resources (pp. 77-102). Springer. https://doi.org/10.1007/978-3-319-06326-3_4

Mantyka-pringle, C. S., Martin, T. G., \& Rhodes, J. R. (2012). Interactions between climate and habitat loss effects on biodiversity: a systematic review and meta-analysis. Global Change Biology, 18(4), 1239-1252. https://doi.org/10.1111/j.1365-2486.2011.02593.x

Matarrese, R., De Pasquale, V., Guerriero, L., Morea, A., Pasquariello, G., Umgiesser, G., Scroccaro, I., \& Alabiso, G. (2004). Comparison between remote-sensed data and in situ measurements in coastal waters: The taranto sea case. Chemistry and Ecology, 20(3), 225-237. https://doi.org/10.1080/02757540410001689795

Mavruk, S., Bengil, F., Yeldan, H., Manasirli, M., \& Avsar, D. (2017). The trend of lessepsian fish populations with an emphasis on temperature variations in Iskenderun Bay, the Northeastern Mediterranean. Fisheries Oceanography, 26(5), 542-554.

https://doi.org/10.1111/fog.12215

Olson, D. M., \& Dinerstein, E. (2002). The Global 200: Priority Ecoregions for Global Conservation. Annals of the Missouri Botanical Garden, 89(2), 199. https://doi.org/10.2307/3298564

Onset. (2019). HOBOware ${ }^{\circledR}$ User's Guide (3.7.18; p. 226). Onset Computer Cooperation.

Orain, F., \& Picart, E. S. (2019). Producst User Manual for SST Level 3 products over European Seas.
Pearson, R. G., \& Dawson, T. P. (2003). Predicting the impacts of climate change on the distribution of species: are bioclimate envelope models useful? Global Ecology and Biogeography, 12(5), 361-371. https://doi.org/10.1046/j.1466-822X.2003.00042.x

Ricciardulli, L., \& Wentz, F. J. (2004). Uncertainties in sea surface temperature retrievals from space: Comparison of microwave and infrared observations from TRMM. Journal of Geophysical Research, 109(C12), C12013. https://doi.org/10.1029/2003JC002247

Sih, A., Jonsson, B. G., \& Luikart, G. (2000). Habitat loss: ecological, evolutionary and genetic consequences. Trends in Ecology \& Evolution, 15(4), 132-134. https://doi.org/10.1016/S0169-5347(99)01799-1

Smale, D., \& Wernberg, T. (2009). Satellite-derived SST data as a proxy for water temperature in nearshore benthic ecology. Marine Ecology Progress Series, 387, 27-37. https://doi.org/10.3354/meps08132

Smit, A. J., Roberts, M., Anderson, R. J., Dufois, F., Dudley, S. F. J., Bornman, T. G., Olbers, J., \& Bolton, J. J. (2013). A Coastal Seawater Temperature Dataset for Biogeographical Studies: Large Biases between In Situ and Remotely-Sensed Data Sets around the Coast of South Africa. PLOS ONE, 8(12), e81944. https://doi.org/10.1371/journal.pone.0081944

Snelgrove, P. V. R., Thrush, S. F., Wall, D. H., \& Norkko, A. (2014). Real world biodiversity-ecosystem functioning: a seafloor perspective. Trends in Ecology \& Evolution, 29(7), 398-405.

https://doi.org/10.1016/j.tree.2014.05.002

Stobart, B., Mayfield, S., Mundy, C., Hobday, A. J., \& Hartog, J. R. (2015). Comparison of in situ and satellite sea surfacetemperature data from South Australia and Tasmania: how reliable are satellite data as a proxy for coastal temperatures in temperate southern Australia? Marine and Freshwater Research, 67(5), 612. https://doi.org/10.1071/MF14340

Thakur, K. K., Vanderstichel, R., Barrell, J., Stryhn, H., Patanasatienkul, T., \& Revie, C. W. (2018). Comparison of Remotely-Sensed Sea Surface Temperature and Salinity Products with in Situ Measurements from British Columbia, Canada. Frontiers in Marine Science, 5:121, 111. https://doi.org/10.3389/fmars.2018.00121

Trapletti, A., \& Hornik, K. (2019). tseries: Time Series Analysis and Computational Finance (p. R package version 0.1047).

Unal, V., \& Kizilkaya, Z. (2019). A Long and Participatory Process towards Successful Fishery Management of Gökova Bay, Turkey. In C. C. Krueger, W. W. Taylor, \& S. J. Youn (Eds.), From Catastrophe to Recovery: Stories of Fishery Management Success (pp. 509-532). American Fisheries Society.

Von Schuckmann, K., Le Traon, P.-Y., Smith, N., Pascual, A., Djavidnia, S., Gattuso, J.-P., Grégoire, M., Nolan, G., Aaboe, S., Aguiar, E., Álvarez Fanjul, E., Alvera-Azcárate, A., Aouf, L., Barciela, R., Behrens, A., Belmonte Rivas, M., Ben Ismail, S., Bentamy, A., Borgini, M., ... Zuo, H. (2019). Copernicus Marine Service Ocean State Report, Issue 3. Journal of Operational Oceanography, 12(sup1), S1S123. https://doi.org/10.1080/1755876X.2019.1633075

Zuur, A., leno, E. N., Walker, N., Saveliev, A. A., \& Smith, G. M. (2009). Mixed Effects Models and Extensions in Ecology with $R$. Springer. 